\title{
Trabajo social, sociopraxis y metodologías participativas: retos, oportunidades y transiciones de lo local a lo global
}

\section{Social Work, Sociopraxis and Participatory Methods: Challenges, Opportunities and Transitions from Local to Global}

\author{
Antonio Álvarez-Benavides \\ John Jay College of Criminal Justice, The City University of New York, \\ Estados Unidos \\ GRESCO-UCM, España \\ aalvarezdebenavides@jjay.cuny.edu \\ alvarezbenavides@gmail.com
}

Resumen: La historia del trabajo social (TS) en España está condicionada por el papel de la Iglesia y del catolicismo en la concepción epistemológica y práctica de la asistencia social y del TS. Esta historia ha tenido una serie de consecuencias, como la tardía institucionalización de la profesión, las dificultades de su incorporación a las universidades y su equiparación con otras ciencias sociales. Estos procesos, a su vez, han provocado dos fenómenos que tienen una dimensión interna y externa: el asistencialismo y la protocolización. Sin embargo, un nuevo contexto de equiparación del TS con el resto de estudios universitarios a través del Espacio Europeo de Educación Superior (EEES) y las transformaciones sociales durante y después de la crisis económica invitan al replanteamiento de la profesión y de la ciencia. Este texto pretende ser una reflexión sobre las potencialidades de la sociopraxis y de las metodologías participativas en dicha reformulación, como puntos de partida y herramientas para plantear una nueva relación entre trabajadores/as sociales y destinarios. Además, se analizarán las posibilidades de transformación social que promueven estas epistemologías y metodologías en la práctica profesional, formativa y académica del trabajador/a social en el ámbito local, comunitario y en la sociedad en su conjunto.

Palabras clave: Trabajo social, asistencialismo, protocolización, metodologías participativas, sociopraxis, transformación social. 


\begin{abstract}
The history of Social Work in Spain is conditioned by the role of Catholicism in the epistemological and practical conception of social assistance and social work. This history has had several consequences: late institutionalization and professionalization, and difficult incorporation to the universities compared to other social sciences. These processes have caused internal and external results: assistentialism and protocolization. However, a new context in which Social Work has been equated with university studies through the EHEA and social transformations due to the economic crisis invites us to rethink Social Work as a profession and as a science. This text aims to reflect on the potentialities of sociopraxis and participatory methodologies in such reformulation, as the starting points and tools to pose a new relation between social workers and stakeholders. It will also analyze the capacity of social transformation promoted by these epistemologies and methods in the social worker professional, formative, and academic practice in the local and communitarian sphere and the whole society.
\end{abstract}

Keywords: Social Work, assistentialism, protocolization, participatory methods, sociopraxis, social transformation. 


\section{INTRODUCCIÓN}

El TS, por su epistemología y por su desarrollo histórico, es una ciencia social especialmente compleja. Su singularidad reside en que en los procesos de intervención social la cercanía entre el/la trabajador $/ \mathrm{a}^{1}$ y el sujeto de la intervención provoca que las acciones y la agencia sean necesariamente compartidas. Al igual que en otros países, en España esta cercanía ha generado malas interpretaciones del TS por las que, lejos de entenderse como un proceso de corresponsabilidad, se ha inclinado hacia dos situaciones negativas: el asistencialismo y la protocolización.

El asistencialismo es una actitud paternalista que parte de los trabajadores/as sociales, de sus «clientes» o de ambos. Esta práctica surge por la necesidad de solucionar problemas graves, muchas veces sobrevenidos, y de hacerlo cuanto antes, en detrimento de los procesos de reconstrucción, de reeducación y de empoderamiento de los actores, en un recorrido protagonizado por el trabajador/a social. La falta de dotación presupuestaria y la saturación de los servicios sociales y la falta de tiempo suficiente para atender cada caso son determinantes a la hora de imposibilitar una gestión compartida de las intervenciones. Por otro lado, una cultura de influencia católica y un TS que se articuló desde la Iglesia o instituciones afines, bajo la premisa de la caridad, sin una visión proactiva de la transformación social, han provocado que muchos de los sujetos a los que atienden los trabajadores/as sociales acudan con la intención de que los problemas le sean resueltos y con poca motivación para involucrase de manera activa en los procesos de transformación. Además, la cultura familiarista de nuestro país y la concepción del género y de los cuidados (Martín Palomo, 2008) han contribuido también a que el imaginario de la atención social se incline muchas veces hacia este asistencialismo.

La protocolización es otra forma común de desvirtuación de la acción social transformadora, que es la base ontológica y deontológica del TS. Con el paso del TS de las parroquias y las organizaciones religiosas a los servicios sociales y a la universidad a finales de los 70 y 80, el TS comenzó a profesionalizarse, sin embargo, este proceso llevó, en muchos casos, a la burocratización. La necesidad de articular nuevas respuestas a necesidades tradicionales, pero también a nuevas realidades y problemas sociales,

\footnotetext{
${ }^{1}$ Aunque a lo largo del texto se ha intentado primar el lenguaje inclusivo no sexista, por cuestiones de economía lingüística, la limitación del espacio tasado de los textos científicos y por agilizar la lectura del texto, se ha utilizado el masculino universal, excepto al referirnos a los trabajadores y trabajadoras sociales. Se consideró utilizar para este caso concreto exclusivamente el femenino puesto que el número de mujeres que ha ejercido y que ejerce esta profesión es mucho mayor que el de hombres, sin embargo, para no crear confusiones se ha decidido utilizar la fórmula convencional de «trabajador/a, trabajadores/as».
} 
de construir marcos teóricos y procesos científicos de intervención de referencia y, en definitiva, de fijar las bases teóricas y profesionales del TS en España, tuvo como consecuencia negativa que muchos de los procesos, las actuaciones y las intervenciones se acabaran estandarizando.

Con el cambio del milenio el TS ha vuelto a vivir una transformación, al igualarse definitivamente al resto de las ciencias sociales en el ámbito académico, equiparándose los niveles de formación, los programas de estudios y acreditándose másteres y programas de doctorado específicos. Este nuevo contexto es una oportunidad excepcional para el TS como profesión y como ciencia, pero también para la transformación social, que es su sustrato primigenio. Puesto que además no existe ciencia social más práctica que el TS, la sociopraxis y las metodologías participativas como principios de acción y herramientas suponen una oportunidad para romper con las bases de la diferenciación entre sujetos que hacen y sujetos que reciben, con el asistencialismo y la protocolización, para potenciar y retroalimentar la necesidad que tiene el TS de dar un salto cualitativo y la sociedad de encontrar en las ciencias sociales el camino para el cambio.

En este texto se reflexionará desde una perspectiva eminentemente teórica sobre las potencialidades que la sociopraxis y las metodologías participativas ofrecen al TS como una ciencia social del siglo xxi. El objetivo fundamental no es proponer un catálogo de técnicas o exponer una serie experiencias concretas, sino intentar mostrar la poderosa capacidad transformadora del TS, desde lo micro a lo macro, desde lo local y lo cotidiano, a la realidad social en su conjunto. Para ello, se hará un breve repaso de la historia reciente del TS en España, examinando los condicionantes y acontecimientos que han lastrado su desarrollo profesional y científico, inclinándolo hacia paradigmas epistemológicos y hacia metodologías poco participativas. A continuación, se reflexionará sobre otras aproximaciones epistemológicas, tanto nacionales como internacionales, entre las que se destacará la sociopraxis como una alternativa imprescindible para el TS. Por último, se vincularán las transformaciones que sustentaría la sociopraxis y su dimensión metodológica - en los servicios sociales y en la universidad, en la práctica y en la formación profesional y científica - con la capacidad del TS de posibilitar una sociedad más justa, más participativa y más democrática².

${ }^{2}$ Este artículo se escribió antes de que se iniciara la pandemia del COVID-19, aunque el proceso de revisión y las correcciones finales se han realizado entre marzo y septiembre de 2020. Para respetar el contenido del artículo que se evaluó se ha decidido no hacer menciones directas a este acontecimiento. En todo caso, las consecuencias sociales y económicas de estos primeros meses y de los que vendrán parecen plantear un escenario similar al de la crisis de 2008 y la postcrisis. Todo ello reiteraría e incluso enfatizaría la línea argumental que se expone a lo largo del artículo en relación con el TS, la sociopraxis y las metodolo- 


\section{EL TS EN ESPAÑA: DE LA CARIDAD A LA INTERVENCIÓN CIENTÍFICO- SOCIAL}

El TS en España está fuertemente influido desde dentro y desde fuera por su historia y por su relación con la Iglesia, el catolicismo y su concepto de caridad. Así, la mentalidad que se deriva de esta relación y de esta concepción del TS no solo está presente dentro de la profesión, sino que es culturalmente mayoritaria.

La evolución del TS no es lineal y ha habido tradiciones, epistemologías, prácticas, paradigmas y valores éticos variados a lo largo de su historia (Idareta, Úriz y Viscarret, 2017). Sin embargo, más allá de las influencias liberales y socialistas, de los distintos instrumentos de protección social que se han ido experimentando y desarrollando a lo largo de la historia del Estado español, la influencia de la Iglesia católica — singularmente durante la dictadura franquista y hasta que se desligó completamente de la profesión - ha sido determinante durante el proceso de institucionalización del TS. En consecuencia, el desarrollo del TS en España como profesión y como disciplina académica ha sido mucho más lento que en otros países de nuestro entorno y ha estado condicionado por estos aspectos políticos, religiosos, sociales y culturales particulares (Martín y de la Fuente, 2016). La concepción privada y privatista de la asistencia social, basada en la caridad y la beneficencia, y la falta del reconocimiento de la mayoría de los derechos civiles, políticos y sociales propios de la ciudadanía hasta la Transición democrática, han articulado un sentido específico del TS en España ${ }^{3}$.

gías participativas y su capacidad de plantear nuevas formas de intervención que a su vez provoquen transformaciones sociales de amplio espectro.

${ }^{3}$ En este pequeño apartado no se pretende analizar el papel de la Iglesia católica en el desarrollo del TS en España ni siquiera de manera resumida. Tanto por el abanico temporal como por la cantidad de actores, acontecimientos y actuaciones, sería necesario un análisis exhaustivo para no caer en reduccionismos. En ese sentido, cuando se afirma una tendencia o una significación social que tiene que ver con una concepción específica de la intervención social, en este caso sobre la influencia de la concepción católica de la caridad en el asistencialismo, se hace en un sentido generalizado. Se considera que ha sido determinante para articular dicha significación, que es compartido por un gran número de actores (en este caso trabajadores/as sociales y destinatarios) y que, en gran medida, se ha institucionalizado en la práctica, en la formación y en la intervención social. No se pretende minimizar ni homogeneizar la labor de muchos profesionales que desde dentro de la Iglesia católica o bajo su influencia construyeron las bases del TS español, desde tendencias y concepciones plurales. No se quiere, en ningún caso, desdeñar el trabajo y las acciones en pro de la justicia social y de la atención de las necesidades que realizaron y realizan distintos colectivos, agrupaciones, congregaciones, parroquias, etc. — que forman parte o se relacionan con la Iglesia-, muchas de ellas desde lo local, con prácticas participativas y con una intención transformadora. En España y, sobre 
Durante la Transición, la evolución del TS fue meteórica, especialmente en el sentido de su institucionalización en un contexto democrático. Es cierto que este proceso se inició durante la dictadura franquista (Brezmes, 2008), pero bajo el control de la Falange y de la Iglesia católica y, determinado, por tanto, por la religión y por la ideología franquista, como reflejaban los planes de estudios de formación de asistentes sociales hasta 1975 (Molina, 1994). El desarrollo del Estado democrático y la Transición desde una Administración que concebía la protección social como caridad, a un estado de bienestar basado en los derechos sociales, fue determinante para dotar a la profesión de trabajador/a social de un sentido y un contenido diferente. Sin embargo, este tránsito fue complejo y costoso. El trabajo de las Asociaciones Profesionales y de los asistentes sociales durante este periodo fue intenso, pues no se trataba tan solo de redefinir la profesión, de dotarla de nuevos contenidos, de una nueva formación y de un nuevo papel social, sino, a la vez, de desarrollar los servicios sociales dentro de los distintos niveles de la Administración pública (Gil Parejo, 2010; Colomer, 1990). Durante la década de los 80 se producen grandes hitos, como la incorporación del TS a la universidad, la creación de los colegios profesionales y la progresiva pérdida de titularidad de la Iglesia de la protección e intervención social (Gil Parejo, 2004).

A pesar de ello, la concepción que impera en el TS sigue estando muy determinada por el asistencialismo, tanto desde dentro de la profesión como desde fuera, pues las leyes de desarrollo de los servicios sociales que van aprobándose durante los 80 y 90 proyectan la figura del trabajador/a social como la de un interventor, estatuto que se refuerza en los plantes de estudios universitarios (Barbero, 2002). Aunque la caridad desaparece de la concepción del TS por parte de los profesionales - quizá no tanto desde una parte de la sociedad civil—, el asistencialismo se mantiene a través de la burocratización del TS (Sanza Cintora, 2001).

todo, en América Latina, desde la Iglesia y desde la religión, se ha recurrido a la sociopraxis y a las metodologías participativas desde corrientes como la Teoría de la Liberación. Sin embargo, además de la línea argumentativa que relaciona los problemas de asistencialismo y protocolización con base en la historia del TS en España y su proceso de institucionalización, hay un compromiso con los principios democráticos de la laicidad y de los derechos sociales. Tanto la concepción del TS que aquí se expone como las potencialidades que se le asocian bajo la asunción de una epistemología sociopráxica y de unas metodologías participativas, parten, necesariamente, de un sistema político democrático que reconozca la atención social con base en la justicia social redistributiva y en los derechos sociales, a través de intervenciones desde las estructuras estatales dotadas para ello, por profesionales formados desde las universidades, bajo una concepción pública de todos estos procesos e instituciones y asumiendo la laicidad como principio básico e indiscutible de una sociedad democrática. 
Esta concepción asistencial y protocolizada del TS no solo estaba presente en las Administraciones y en los servicios sociales, sino en los propios destinatarios. Como analiza Belén Navarro (2013), son los propios «clientes» los que han reclamado históricamente este papel asistencial al trabajador/a social. Otro ejemplo revelador se produjo durante la crisis económica de 2008, cuando un porcentaje elevado de los ciudadanos que necesitaban recurrir a los servicios sociales eran atendidos por asociaciones religiosas y de caridad, como Cáritas. Sin duda, la mentalidad católica de la caridad continúa estando muy presente en la sociedad española, que sigue concibiendo la pobreza en términos cristianos de culpa y no como una relación de desigualdad estructural cuya reparación depende del Estado con base en una serie de derechos sociales recogidos en la Constitución, por lo que muchas personas deciden acudir a la beneficencia antes que a los servicios sociales. Evidentemente la explicación de que esto suceda es multidimensional, pero el factor cultural-religioso es determinante. La consecuencia es que en un número elevado de casos se plantee el TS en términos de reparación y de emergencia, exclusivamente de necesidades y no de potencialidades. Lo que se espera de los trabajadores/as sociales no es la producción o la articulación de nuevos paradigmas epistemológicos desde los que sustentar la intervención, sino que intervenga y que solucione los problemas.

Durante el cambio de siglo y especialmente durante los últimos años de la primera década se producen dos acontecimientos que son determinantes en el TS español y que suponen un nuevo horizonte de retos y posibilidades. El primero de ellos es la adaptación de los estudios de TS al nuevo EEES y el segundo, la crisis económica que comenzó en 2008. Con la creación del grado en TS, los programas de máster y los doctorados, el TS se equipara por primera vez en España al resto de ciencias sociales y al resto de formaciones universitarias (Aguado, 2005; Gil Parejo, 2005). Es cierto que la labor científica del $\mathrm{TS}^{4}$ se había desarrollado tanto en la universidad como en ámbitos de tra-

${ }^{4}$ Además de como profesión, el TS debía institucionalizarse en el ámbito científico. Desde los años 50 del s. xx, precisamente cuando comenzaba el proceso de institucionalización profesional, surgió un buen número de trabajos científicos que pretendían dar un contenido académico a este proceso, con base en investigaciones, artículos, manuales, metodologías específicas, estudios de caso, etc. Muchos de estos trabajos se recogieron en revistas específicas, como Documentación Social (1956), Treball Social (1968) y ya, en la Transición, Cuadernos de TS (1987), entre otras (Gil Parejo, 2004a). Se constituyeron grupos de investigación y distintos encuentros y congresos científicos (Gil Parejo, 2014). En los años 70 y 80 continuó de manera intensa el desarrollo del ámbito científico de la intervención social, especialmente desde el punto de vista metodológico (Colomer, 1979). Sin embargo, la necesidad de la institucionalización profesional y la forma en que se definieron las funciones y contenidos de la profesión volvió a ser determinante para acercar al TS hacia una actividad más administrativa que científica. Muestra de ello es que a pesar de 
bajo, de estudios y de investigación adyacentes, publicándose también tesis específicas desde programas de sociología o historia (Gil Parejo, 2014), sin embargo, este nuevo contexto permite desarrollar epistemologías, líneas de investigación y estrategias propias (Anaut-Bravo, 2016). El segundo acontecimiento tiene que ver con la crisis económica y con las repercusiones multidimensionales que supone para el TS. Los problemas sociales se multiplicaron en un momento en el que se redujeron drásticamente los presupuestos y dotaciones para los servicios sociales. Sin embargo, este escenario, tanto para los trabajadores/as sociales como para los ciudadanos, puede suponer una oportunidad única para transformar, definitivamente, la concepción del TS, para que la garantía de los derechos sociales y la lucha contra las desigualdades sociales sea liderada desde la primera línea del frente por científicos sociales que tienen en su práctica cotidiana los elementos que configuran su disciplina científica.

\section{LA NECESIDAD DE UNA VERDADERA REFORMULACIÓN EPISTEMOLÓGICA}

La equiparación científica y el escenario de la crisis y la postcrisis ofrecen una oportunidad excelente para hacer un análisis y una reformulación del TS desde dentro. Como cualquier cambio importante, estos dos nuevos contextos brindan oportunidades, retos y riesgos.

Por ejemplo, la crisis económica y la postcrisis pueden redundar negativamente en el asistencialismo. El aumento de las necesidades sociales y de los problemas, unido a la escasez de recursos, podría incrementar la tendencia a tratar los casos rápido, con soluciones estandarizadas y aplicando protocolos más o menos unidireccionales. Pero también puede provocar - y de hecho está provocando - un replanteamiento epistemológico del TS, tanto en sus bases de conocimiento como en sus formas de actuación, apostando por distintas maneras de llevar a cabo la intervención, por ejemplo, a través de la corresponsabilidad y de la participación activa de los ciudadanos. Del mismo modo, la nueva dimensión académica y universitaria del TS, tanto por la cobertura que ofrece a la disciplina como por la necesidad de desarrollar, ampliar y modificar los planes de estudio, podría volver a ser un condicionante interno y externo negativo. Por ejemplo, con la proliferación de «universidades-empresas», que ante un panorama en el

que el TS entra en la universidad a principios de los 80 , lo hace como una diplomatura y no desarrolla planes de doctorado propios como otras ciencias sociales como la sociología, la psicología y la antropología. Los/ as trabajadores/as sociales siguen siendo formados para atender las necesidades sociales de forma inmediata y a través de intervenciones estandarizadas, esto es, de protocolos comunes de actuación. 
que muchos trabajadores/as sociales quieren o necesitan convalidar sus títulos (a través de cursos puentes para pasar de una diplomatura a un grado) o aumentar su nivel de formación (por razones diversas), aprovechan la coyuntura para sacar rentabilidad lejos de plantearse las posibilidades de transformación del TS. Efectivamente, el binomio crisis económica y nuevos espacios universitarios ha tenido ciertas consecuencias perversas, tanto para alumnos como para profesores, y el TS ha sido una víctima singular de este proceso. Las necesidades de unos y otros, la posibilidad de acelerar los procesos, reducir a un mínimo aceptable los contenidos, las concomitancias entre poderes económicos y políticos y, en definitiva, la lógica empresarial capitalista han hecho que los nuevos espacios de formación, investigación y reflexión académica no siempre sean ocupados de la mejor manera y con los más nobles intereses.

Pero, precisamente, luchar contra las visiones y posiciones negativas e imposibilistas de la realidad también es uno de los frentes de acción fundamentales del TS, pues no hay nada más alejado de la ontología del TS que plantear una realidad, por negativa que sea, como imposible de ser transformada. Afirmar la realidad como inmutable y sin alternativas es uno de los grandes logros del neoliberalismo, de forma que las desigualdades estructurales se conciben como naturales, a través de un proceso de aceptación social que aparentemente no ofrece resistencias (Álvarez-Benavides, 2005, 2012).

La universidad es una herramienta esencial en la producción de ideología y sentido, por lo que, más allá de las resistencias y de los intereses espurios, el TS debe plantearse como una profesión y una actividad científica posibilista, cuya misión no consiste solo en atender las desigualdades sociales, sino en hacerlas explícitas, denunciarlas, pero sobre todo en trabajar colectivamente para erradicarlas. La universidad tiene que ser un vector fundamental en la transformación del TS, en la redefinición de sus funciones y en sus paradigmas de conocimiento y de acción. El contexto universitario, académico, los planes de doctorado, el replanteamiento de la formación, posibilitan una cobertura para que el TS se vuelque también en su labor científica, una dimensión de la disciplina que ha estado eclipsada por la práctica profesional. En este sentido, la reflexión epistemológica resulta imprescindible para iniciar cualquier proceso de transformación de cualquier actividad científica.

La revisión de la epistemología implica cierto grado de revolución dentro de cada ciencia. Este grado puede cambiar las propias bases del conocimiento científico de un determinado campo, como hizo la teoría de la relatividad con la física newtoniana, o puede constatar tradiciones que llevaban tiempo vislumbrándose o desarrollándose, como supuso, por ejemplo, el interaccionismo simbólico para la sociología. Cuando nuestro objeto de estudio son las personas, un cambio de paradigma puede transformar la relación con ese objeto, convirtiéndolo en sujeto, pero además puede cambiar incluso la forma en que se produce el conocimiento, pasando no solo a una relación sujeto-su- 
jeto, sino a una actividad científica colaborativa resultado de la interacción y de la inteligencia compartida. Estas epistemologías, esta manera de entender tanto el proceso como las fuentes del conocimiento científico, no son revolucionarias y han sido recurrentes en la filosofía, en la sociología, en la psicología, en la antropología y en el TS. Los estudios migratorios, por ejemplo, dieron un salto muy rápido desde lo cuantitativo a lo cualitativo cuando prácticamente se acababa de asentar el método sociológico (Thomas y Znaniecki, 1918/2004). La antropología, desde sus inicios, utilizó la etnografía y la observación participante como su metodología básica y fundamental y, por tanto, como su fuente de conocimiento (Bruyn, 1968). La fenomenología de Schütz en los años 30 ya señalaba la inevitable dimensión social del conocimiento, su producción social y colectiva (1932/1998); como el de la realidad, que luego constatarían Berger y Luhmann (1968/1999). La producción participativa del conocimiento y la investigación-acción-transformación grupal también tienen precedentes muy lejanos en el tiempo (Rahman y Borda, 1998). Han pasado casi cien años desde que Kurt Lewin empezara a experimentar la «research action» (Marrow, 1977; Aldeman, 1993). Desde entonces su desarrollo se ha producido desde distintas disciplinas — no solo desde las ciencias sociales, aunque siguiendo estos paradigmas, en realidad, cualquier conocimiento y cualquier práctica es social-, en distintos contextos y con objetivos muy variados.

Dentro de estas tradiciones cabe destacar la latinoamericana, pues se articula además como una práctica liberadora (Freire, 1982). La producción de conocimiento compartido tiene un componente reparativo, pero la acción es eminentemente crítica y con pretensión transformadora. La educación popular y la pedagogía liberadora, que surgen en Brasil hace casi ya sesenta años (Rodrigues Brandão, 2015), representada por su más reconocido exponente, Paulo Freire, señala y desarrolla una forma de entender y trabajar con la realidad social, en la que los destinatarios son también protagonistas y en la que los educadores aprenden enseñando. El fin último es la transformación de una realidad injusta, el desarrollo personal y comunitario, no en el sentido capitalista y liberal, sino en la experiencia de los oprimidos. En definitiva, aprender a ser libres siendo libres. Desde algo aparentemente tan sencillo, que se justificaba en adaptar a la realidad de aquel tiempo lo que en cierta manera se venía haciendo desde siempre, surgió toda una revolución epistemológica y metodológica que afectó a disciplinas aparentemente tan alejadas como la arquitectura y la psicología, la ingeniería agraria e hidráulica y la medicina, incluso a la religión. Por supuesto, el TS no iba a ser ajeno a estos cambios.

$\mathrm{La}$ «Reconceptualización del TS» es, precisamente, la adaptación de estas epistemologías y de las metodologías que surgieron a partir de ellas al TS. Surge como una manera distinta de entender la práctica del TS y los servicios sociales, reconociendo la necesidad de entrar en una nueva fase. Este proceso, que se produce aproximadamente 
entre 1965 y 1975, tiene un carácter autorreflexivo, puesto que son los propios trabajadores/as sociales los que se plantean la necesidad de pensar y concebir el TS de otra manera. El sentido de la Reconceptualización es idóneo para ejemplificar el tránsito inconcluso del TS en España expuesto más arriba, pues se basa en la necesidad de profundizar en el carácter científico de la disciplina, y desde el conocimiento científico de la realidad y los fenómenos sociales hacer conscientes a los sujetos de sus realidades personales y colectivas para facilitar y desarrollar el cambio (Vera Quiroz, 2020: 131). Además, uno de los ejes centrales de la Reconceptualización es reconocer que el TS tiene un carácter político (Quintero, 2014, 2018). Esta cuestión se aborda en dos sentidos (Ander-Egg y Kruse, 1984) totalmente extrapolables al momento actual. Por un lado, la Reconceptualización surge y se desarrolla en un momento en el que América Latina sufre las consecuencias negativas de los planes de desarrollo capitalista en la región, y por otro, porque el trabajador/a social trataba los problemas que se generaban desde una perspectiva individualista, como patologías cuyo origen social, estructural y político no era afrontado (Ander-Egg y Kruse, 1984). Aunque las posturas son diversas y los debates intensos, «el planteo se centra en que los sujetos cambian colectivamente, por la concientización, por la organización y por la producción de una nueva cultura que los vuelva protagonistas de la historia. En esta perspectiva no es el problema el foco principal de acción sino el agente, quien pasa a ser el referente del cambio. El cambio propuesto es: pasar de sumiso a protagonista, de ingenuo a crítico, de alienado a consciente, de aislado a organizado» (Del Prado y Rivero, 2019: 115-116).

La relación entre lo individual y lo colectivo, la compresión de las desigualdades desde lo político y desde el conocimiento científico, la potencialidad de transformar desde lo micro y lo macro, desde lo local y lo cotidiano, lo global y lo institucional, son cuestiones centrales en los debates que se tuvieron dentro de la Reconceptualización. A su vez, son paradigmas y preceptos estructurales de las sociopraxis y de las metodologías participativas. Pensar en el TS desde estos paradigmas implica entender la realidad social y la producción del conocimiento de manera distinta. La dimensión colectiva de los problemas es a su vez el origen de las soluciones. Los procesos son a su vez compartidos, coprotagonizados, y los resultados, los cambios, se producen tanto en el ámbito individual como en el colectivo.

\section{LA SOCIOPRAXIS Y LAS METODOLOGÍAS PARTICIPATIVAS APLICADAS AL TS}

Estas epistemologías llegaron tarde a España, tanto al TS como a otras disciplinas. La influencia de la teoría de la liberación y su relación con el socialismo y el marxismo 
no eran muy bien vistas en la dictadura. En el periodo de la Transición, mientras que el TS se convertía en una profesión en España, en América Latina seguían discutiendo sobre la necesidad de refundar su ontología y su deontología, esto es, tanto su ser como su forma de obrar. No podemos hablar, por tanto, de una verdadera corriente reconceptualista en España, aunque sí de investigadores, profesionales y colectivos que, en pequeñas redes, en el ámbito académico y en procesos locales, experimentaron estas epistemologías y metodologías.

Entre los primeros investigadores que empiezan a utilizar las metodologías implicativas y, concretamente, la Investigación Acción, está Ángel Montes del Casti1lo, quien desde la antropología (Del Castillo, 1993), pero también desde el TS (Del Castillo, 1996; 2000), reflexiona sobre la necesidad de hacer explícitas las contradicciones estructurales del sistema, considerando la práctica del TS un ámbito privilegiado desde el que hacerlo. Del Castillo repasa de manera sistemática todos los desarrollos teóricos y los tipos de acción social, constando la necesidad de superar los modelos de intervención y de investigación tradicionales basados, como señalaba Kruse, en una concepción capitalista del desarrollo, para plantear las intervenciones desde la sociedad en su conjunto hasta los individuos y los colectivos en situación de exclusión, desde lo micro a lo macro, y viceversa. Paloma López Ceballos es otra de las pioneras en pensar el TS desde la práctica liberadora, haciendo hincapié en la dimensión práctica de estos procesos. Los trabajos de Del Castillo tienen un componente teórico esencial para conocer tanto los debates de los años 60 y 70 como sus desarrollos posteriores; los de López Ceballos, para conocer sus primeros desarrollos prácticos en España, pues explica las potencialidades del método, sus características, sus aportes al TS, y además recopila distintas experiencias que ya desde los 70 estaban explorando estas metodologías (López Ceballos, 1987).

En una posición intermedia estaría Tomás R. Villasante, quien a través de una vasta producción combina la reflexión teórica y el diseño metodológico (Villasante, 1993; 2007 ; 2 2007b) con la práctica de la IAP y la recopilación de experiencias nacionales e internacionales (Pinto y Villasante, 2011). Desde la Universidad Complutense como profesor y a través de la fundación en los años 80 de la Red CIMS, que, posteriormente, daría lugar al Observatorio de Ciudadanía y Medio Ambiente Sostenible (CIMAS) ${ }^{5}$, Villasante, junto alumnos y compañeros, inicia procesos participativos en el ámbito local, en distintos barrios, localidades, municipios, tejiendo una red de experiencias, pro-

\footnotetext{
${ }^{5}$ http://www.redcimas.org
} 
fesionales e ideas que serán fundamentales para comprender el desarrollo de la IAP y de las metodologías participativas en España.

La propuesta que subyace detrás de todas estas corrientes es que, una vez asumida la epistemología, la puesta en marcha de la intervención social colaborativa y participativa surge de la creatividad social. El modelo que proponen autores como Manuel Montañés y Pedro Martínez (2017), el propio Villasante (2007a) o el colectivo CIMAS (2015), no difiere en exceso del de una investigación-intervención tradicional, pues surge de una negociación, tras la que se recaba información a través de distintas metodologías, se analiza dicha información, se hace un diagnóstico y a partir de éste se articula una planificación y, por último, una evaluación. Una de las características fundamentales de estos procesos es la pluralidad de técnicas para la recogida de información y para la planificación creativa, además de las clásicas cuantitativas y cualitativas. También destacan otras dos cuestiones fundamentales. La primera es que todo el proceso es compartido, no solo porque la población objeto de la intervención participa activamente en todas las fases, desde la recogida de información y de los «dolores» (Curbelo y Hernández, 2017: 62-80) hasta la planificación, ejecución y evaluación, sino porque el equipo investigador-interventor de la IAP se constituye como un grupo-motor (Villasante, 2015; CIMAS, 2015), formado tanto por los metodólogos como por agentes sociales destinatarios de la intervención. La segunda es que antes del proceso de creatividad social, que constituirá el inicio de la planificación, el diagnóstico se devuelve. La devolución es una parte indispensable del proceso, pues implica corroborar y ajustar el análisis con los destinatarios — con los sujetos de dicho diagnóstico-, es decir, hacerlo suyo. De esta manera, la puesta en marcha del proceso, la intervención, su mantenimiento y su evaluación a lo largo del tiempo es un camino compartido, en el que los protagonistas son los destinatarios y los metodólogos son acompañantes.

En las últimas cuatro décadas se han hecho intervenciones y procesos de todo tipo, tanto en España como en Latinoamérica. En el ámbito del desarrollo ecológico y urbano sostenible destacan las Agendas 21 (García-Montes y Arnanz, 2019). Se trata de planes de desarrollo local hechos de manera participativa y que tienen un recorrido de ya casi veinte años (Garrido, 2005). En el ámbito económico, los presupuestos participativos (Villasante, Garrido y Hernández, 2002) se han convertido en una herramienta de gestión presupuestaria participativa ampliamente aceptada a nivel social y ejecutada por Administraciones de todas las orientaciones ideológicas. También se han abierto procesos en los servicios sociales, de tipo sanitario, agrícola, urbanístico, convivencial, artís- 
tico, etc. ${ }^{6}$. Las experiencias y los ámbitos de aplicación son tan diversos como las metodologías.

Las metodologías participativas se conciben como herramientas que posibilitan la producción de información, de conocimiento colectivo sobre situaciones y sujetos diversos. De la misma manera que la epistemología parte de la complejidad social, las metodologías tienen su razón de ser en dicha complejidad social. Hay muchos manuales (CIMAS, 2015; Montañés, 2011) en los que se recogen tanto experiencias como técnicas concretas, muchas de ellas ya clásicas y de uso común en ámbitos alejados de la intervención participativa y del TS como el método DAFO (CIMAS, 2015), el flujograma (Socas, 2003) o el sociograma (Martín y Villasante, 2007); y otras cuyo desarrollo proviene de la tradición latinoamericana y del TS crítico, y que están muy influidas por su contexto, como el teatro del oprimido (Boal, 2013) o los juegos y dinámicas de rol y sus derivados (Sucari, 2017; Martínez y Camas, 2015). No se pretende aquí hacer un catálogo de las distintas metodologías ni tampoco de las distintas experiencias, pues proponer «recetas» concretas para situaciones o procesos específicos redundaría en la protocolización y estandarización del TS; se trata de trazar las bases sobre las que se articulan estas metodologías como facilitadores y explicar sus potencialidades para el TS. Tampoco se pretende transformar drásticamente el TS o plantear una visión radical y rompedora, sino más bien reflexionar sobre los axiomas y sobre cómo éstos condicionan la práctica en el terreno y en/desde la academia.

De hecho, estas formas de proceder basadas en una manera de acceder y producir el conocimiento (epistemología práxica), a través de unos modelos de investigación-intervención (IAP), que utilizan unas metodologías implicativas más o menos novedosas (metodologías participativas), son fácilmente extrapolables al TS en todas sus dimensiones. En este sentido, uno de los textos que han conjugado de manera más crítica y propositiva el trinomio TS, sociopraxis y metodologías participativas es «Otro Trabajo Social es posible», de Álex Curbelo y Loli Hernández (2017). El libro tiene muchas cosas interesantes. La primera de ellas es que está escrito en primera persona y con un leguaje muchas veces alejado de la convencionalidad académica, lo que le confiere un tono directo y poderoso. Pero sobre todo que pone el foco de atención en el trabajador y la trabajadora social como sujeto y actor social, además de como profesional. Los dos autores son trabajadores/as sociales y Loli Hernández ha sido durante muchos años

${ }^{6}$ En la biblioteca virtual de la Red CIMAS se puede encontrar decenas de documentos de acceso libre sobre distintas experiencias, metodologías y debates teóricos. Ente ellos destaca la colección «Construyendo ciudadanía» de la Red, que surge en el año 2000 y cuenta con quince volúmenes. 
profesora de TS en la universidad, formadora en metodologías participativas y ha participado en decenas de procesos participativos en España y América Latina. Su diagnóstico de la realidad del TS en España no difiere mucho del presentado aquí: una práctica profesional dominada muchas veces por el asistencialismo, marcada, por tanto, por una forma concreta - construida - de entender la realidad social y por una tendencia a la estandarización y al trabajo no implicativo en los casos. Esta protocolización se relaciona también, según los autores, con una concepción errónea de los tiempos, pues se piensa que dar una solución con base en protocolos estandarizados o a la experiencia personal reduce los tiempos de atención y permite atender más casos, sin embargo, la durabilidad de los resultados es menor y, por tanto, se seguirán acumulando casos y se redundará en la práctica asistencial. Más allá del contexto, el libro es un alegato de lo que el trabajador/a social puede hacer no solo en su práctica cotidiana y en su implicación directa con los casos — para cambiar la práctica del TS—, sino para transformar la realidad social en su conjunto. Curbelo y Hernández insisten en que debemos superar el TS individualizador y culpabilista y entenderlo no como un tú y un yo, sino como una relación creativa y reflexiva. De esta manera, no se pueden plantear los casos dentro del TS como sujetos extraídos de su contexto, al igual que no se pueden entender a los trabajadores/as sociales, sus intervenciones y los servicios sociales como actores encapsulados, en suspenso, o ajenos de la realidad social que les circunda y con la que se imbrican. Así, Hernández y Alex (2017: 55-56) afirman: «Cualquier profesión social está envuelta en muchos valores, ideologías, paradigmas y contextos diferentes, aparte de las características personales y trayectoria profesional de cada persona que la ejerce. Esto es evidente, pero se suele olvidar en la práctica cotidiana, muchas veces con la disculpa de las prisas, de las urgencias o de las exigencias de la institución donde se trabaja. Ese olvido no nos permite reflexionar sobre el para qué estamos trabajando, ese para qué que nos marca, queramos o no, nuestra forma de actuar, de ejercer, de reaccionar ante una problemática social cualquiera. También nos direcciona la relación con la institución que nos pone las reglas de juego y los recursos materiales con los que trabajar».

Las metodologías participativas y la sociopraxis no se plantean realmente como lugares a los que llegar, sino de los que partir. No hay una necesidad específica de formación previa, sino más bien una especie de desconstrucción de lo aprendido o de lo asimilado para ejercer un TS liberador para el destinatario, para el trabajador/a y para la sociedad en su conjunto. Las técnicas pueden aprenderse y pueden ser facilitadores, pero lo realmente importante es la actitud. Apostar por la sociopraxis como epistemología y las metodologías participativas como métodos de investigación/intervención supone apostar por las potencialidades de los sujetos, de los trabajadores/as sociales y del TS. El TS implica escucha activa, negociación, de/re/construcción, pero es siempre un 
proceso compartido, una relación sujeto-sujeto, en el que el yo y el tú se mezclan, en el que las fronteras se difuminan. Desde ahí, el campo de acción se vuelve infinito.

\section{DEL INDIVIDUALISMO AL DESBORDE CIUDADANO, DE LAS TRASFORMACIONES LOCALES A LAS GLOBALES}

Cuando hablamos de la dimensión participativa del TS, de las corrientes críticas, solemos relacionarlo con el TS comunitario, pero debemos ir más allá de este pensamiento o al menos reorientarlo. Parece más sencillo pensar en los procesos participativos exclusivamente desde el TS comunitario. De un modo u otro, las acciones colaborativas tampoco están tan alejadas de ciertas prácticas grupales que a lo largo de la vida todo individuo ha tenido más allá de que apueste o no por este tipo de epistemologías y metodologías, o siquiera de que las conozca. Sin embargo, bajo esta visión subyace, como se viene argumentando, una construcción ideológica de lo social. Cuando alguien tiene un problema, ese problema es suyo y, por lo tanto, la solución es también individual - personal - ya venga de fuera o de uno mismo. Ciertamente, todas las intervenciones de casos se plantean ya como intervenciones en las redes próximas (familia, amigos, trabajo), pero podemos y debemos ampliar dichas redes. Debemos romper la dinámica individualista tanto de las intervenciones como de los problemas sociales. Las dinámicas participativas son esenciales para el TS con comunidades, con familias, pero también con individuos, pues si los problemas individuales son también sociales, su intervención debe ser colectiva y colaborativa, desde y hacia el ámbito comunitario. Del mismo modo, los efectos positivos, las soluciones, no solo afectarán al individuo, sino que repercutirán en el conjunto de su comunidad y de la sociedad.

Esta dimensión de la acción social sobre el terreno tiene su correlato en la academia y en la universidad, donde el TS español debe desarrollar todas estas potencialidades. Como señala Lamo de Espinosa (2003), durante la modernidad, el conocimiento científico era un conocimiento burgués; las ciencias, y entre ellas las sociales, se circunscribían a la universidad, a los círculos de expertos. Los científicos hablaban a los científicos y la repercusión de sus investigaciones no afectaba de una manera tan directa como lo hace en la actualidad al público general, que por otra parte es más culto y ha desarrollado unos canales de comunicación inimaginables en otras épocas. Los científicos sociales desarrollaban modelos que pretendían aplicar a distintos campos de lo social, pero no tardaron en darse cuenta de que la difusión de estos modelos alteraba su estatuto ontológico, pasando de ser teorías puras relegadas al ámbito académico a mapas cognitivos (recetas, categorías sociales) usados por los individuos en su cotidianidad 
(etnociencia). Investigar y describir la realidad social significa, por tanto, darle forma, transformarla.

Puesto que el científico social es consciente de que su trabajo como investigador modifica la realidad que está estudiando, surge la necesidad de plantearse su posición respecto al objeto o sujeto investigado. La reflexividad se convierte en el código deontológico del investigador social, lo que implica ser consciente de que los juicios de valor, las creencias, la ideología, nuestra cosmovisión, son parte de esa realidad que se está estudiando. Transformamos la realidad, pero somos conscientes de ello, por lo que nuestro trabajo debería estar orientado, como pensaba Durkheim, hacia la deconstrucción de los preconceptos, prenociones y prejuicios. Emilio Lamo de Espinosa es contundente en sus palabras: «... de modo que no tenemos más alternativa que aceptar que nuestra tarea es ya otra, como señalaba Merton. No describir el mundo, sino hacer lo que de verdad hacemos: llevar luz a los actores, hacer algo más transparente nuestro orden social para que los actores (es decir, nosotros mismos) podamos actuar con menor ignorancia» (Lamo de Espinosa, 2003: 30). Llevar luz a los actores implica entender por qué ciertas categorías han sido planteadas en términos estructurales de inferioridad y de desigualdad, pero además comprender nuestra responsabilidad en la configuración de dichas categorías.

Nuestra forma de entender el TS va a determinar nuestras actuaciones, pero también el tipo de sociedad que mantengamos o construyamos. La epistemología, los modelos y los modos de intervención determinan, queramos o no, la realidad. Son un reflejo de un pasado, de una tradición, se perpetúan en el presente, pero además edifican los cimientos sobre los que se levanta el futuro. El trabajador/a social es un científico social singular, pues investiga e interviene en la realidad al mismo tiempo, en un proceso doble y retroalimentativo de transformación social. Como investigador, debe aclarar la construcción de la realidad social, pero a la vez, como primera línea del frente, su labor principal es trabajar para transformarla, esto es, para que desaparezcan las desigualdades sociales (Borda, 1979). La sociología puede o no ser crítica, la antropología puede limitarse a lo descriptivo y a la interpretación, pero el TS no puede evitar que la objetividad que se le supone a toda ciencia y la necesidad de una actitud reflexiva no vaya acompañada de una posición crítica ante las realidades injustas. El trabajador/a no solo es consciente de que en su quehacer transforma la realidad por su mera presencia, sino que de hecho debe trasformar dicha realidad, pues es su razón de ser.

Esta lógica de hacer haciendo, de transformar transformando, y de ser consciente de ello, está presente en la vida cotidiana y es una de las bases de la complejidad social. Autores como Holloway (2002) hablaban de algo así como hacer una revolución sin necesidad de hacerlo desde las instituciones, sin tomar el poder, puesto que el poder de la transformación social no está solo en el poder institucional, sino también en las rela- 
ciones sociales que se establecen. La práctica profesional y científica del TS no necesitaría, por tanto, transformar de golpe las instituciones encargadas de la protección y de la intervención social, sino que estos cambios se producirían modificando las relaciones con los sujetos con los que se interviene. Lo mismo sucedería estableciendo otro tipo de relaciones con los compañeros, otros profesionales sociales, otros agentes dentro y fuera de los servicios sociales, con el alumnado, con otros colegas y académicos, etc. Practicar otro TS desde los servicios sociales y desde la universidad posibilitaría otro TS, que es posible porque realmente existe y se está practicando.

Geoffrey Pleyers (2019) explica muy bien este proceso cuando analiza los movimientos sociales contemporáneos. Según Pleyers, cuando una serie de individuos viven sus realidades alternativas como realidades cotidianas dentro de la sociedad, no al margen de ella, estas realidades se acaban normalizando, puesto que son, de hecho, una parte de la realidad social. El activismo de lo cotidiano es en sí una transformación social. No se necesita que estas formas de vida alternativa se legitimen a través de la vía política entendida como la política institucional porque están ya legitimadas por el hecho de existir y de ser vividas de manera subjetiva. Pleyers (2019: 45-54) habla de la vía de la subjetividad y de la vía de la razón. La primera de ellas es la de los sujetos que transforman la realidad porque viven de maneras distintas, sus relaciones sociales son distintas, válidas y legítimas. Un ejemplo claro es el ecologismo y el consumo sostenible, pero también formas plurales de amor, compromiso, familia, etc. La otra vía es la vía de la razón, en la que unos intelectuales, activistas y actores políticos piensan mundos posibles y pretenden que éstos se legitimen a través de la política convencional. Ambas vías son complementarias y necesarias, pero es el hecho de que se establezcan formas alternativas de entender la realidad social lo que produce la necesidad de legitimización burocrática, no al revés. No es la política la que posibilita nuevas formas de vivir, como mucho puede legitimarlas en el ámbito político convencional, lo que no deja de ser importante.

Tomás R. Villasante relaciona la influencia de las prácticas subjetivas micro y sus conexiones con transformaciones sociales más poderosas a partir de dos procesos: las experiencias comunitarias y los movimientos sociales, siendo la línea divisoria entre unas y otras cada vez más difusa. En un contexto en el que el capitalismo y el neoliberalismo han desarrollado sus cotas más altas de dominación, los movimientos sociales, pero también colectivos de todo tipo y de toda forma, en todas las partes del globo, no han dejado de contestar esta dominación en su día a día, viviendo otras formas de vida, a través de prácticas diversas. La globalización implica dominación y homogeneización, pero eso no significa que no existan espacios de libertad y de contestación. Como se decía más arriba, la afirmación de que no hay alternativas es uno de los mayores logros 
y pretensiones del capitalismo tardío, pero eso no significa ni que debamos aceptarla (como ciudadanos y como científicos sociales) ni que asumamos que los actores por el hecho de encontrarse en una situación de exclusión o de dominación no se resisten a ser dominados (Sassen 2003). Esa actitud, como la victimización de los actores sociales, implica reproducir el discurso que culpabiliza a los sujetos de su situación de marginalidad (Wiviorka, 2008), reificar, por tanto, la lógica individualista y culpabilista neoliberal y tardocapitalista. Debemos poner el foco de atención en las prácticas de contestación, en la contraacción simbólica y real, en las formas de vida alternativas, en otras maneras de intervenir en la realidad social, pues construyen otras realidades posibles.

El concepto de desborde, tratado ampliamente por Villasante (2014), ahonda en estos procesos de transformación social y tiene además una gran potencialidad para el TS. Los desbordes «creativos o reversivos» se pueden entender como la capacidad de los actores de producir transformaciones sociales desde la cotidianidad y de manera imprevista. Se abandonaría la lógica de la revolución para visibilizar desde lo local, desde lo cotidiano, a través de situaciones concretas, las contradicciones del sistema. Respecto al TS, ante el progresivo desvanecimiento del estado de bienestar, socavado aún más por la crisis económica y por los recortes sociales provocados por su gestión, son los propios actores los que desbordaron el sistema: trabajadores/as, destinatarios y la sociedad civil. El 15M es el ejemplo reciente más importante de la capacidad de desborde de los actores sociales ante una situación en la que parecía que no había alternativas, haciendo visibles otras realidades posibles de manera creativa, colectiva y pacífica. El 15M fue un ejemplo de creatividad y de transformación social que se produjo de manera inesperada, desde la subjetividad y desde lo micro, pues comenzó como un grupo de cuatro personas que se quedaron a dormir en una plaza para convertirse en un movimiento global. La traducción y transformación política vino después, y legitimó institucionalmente lo que ya era legítimo en distintos barrios, comunidades, municipios, colectivos y familias. Ese camino hacia las democracias participativas, que reclamaba el $15 \mathrm{M}$, se está institucionalizando y llevando a cabo desde los nuevos partidos, desde los gobiernos del cambio, desde nuevas orientaciones políticas, pero es imposible e impensable sin esas redes previas, redes amplias, en las que ya se vivía y se viven las democracias participativas de forma cotidiana.

\section{CONCLUSIONES}

La configuración histórica del TS como profesión, los planes de formación y la forma y las funciones que se han atribuido a los servicios sociales han influido de manera 
notable en la profesión, llevándola primero hacia el asistencialismo y luego hacia la protocolización. Sin embargo, el TS ha desarrollado otras concepciones epistemológicas y otras metodologías casi desde su formación, y especialmente a partir de los años 60-70 en América Latina. Esas epistemologías y metodologías se presentan en el texto como herramientas y oportunidades en un contexto propicio para un cambio de rumbo.

La forma de entender, participar y transformar la realidad social iniciada por Freire influyó a distintas disciplinas y tradiciones. La Reconceptualización del TS supuso una manera distinta de entender el papel de TS en la sociedad, así como su forma de conocer e intervenir los problemas sociales. Aunque el desarrollo de esta tendencia fue muy limitado en España, su epistemología y sus metodologías poco a poco fueron siendo experimentadas en distintos ámbitos y desde distintas disciplinas, por lo que casi cuarenta años después su desarrollo ha planteado nuevas posibilidades en nuevos escenarios. $\mathrm{Si}$ la Reconceptualización por el contexto y los tiempos en los que se produjo — golpes de Estado, dictaduras militares - estuvo determinada por la lógica de la revolución, la sociopraxis no plantea que estos cambios tengan que producirse de manera abrupta. Ambas perspectivas comparten la idea sobre la manera en que el TS accede al conocimiento de la realidad social, el diagnóstico de dicha realidad social, la concepción colectiva de los problemas, los procesos y las soluciones, así como muchas de las metodologías de intervención/transformación social. Sin embargo, la sociopraxis en el contexto actual en España no promueve, necesariamente, procesos revolucionarios.

La sociopraxis y las metodologías participativas plantean una relación sujeto-sujeto en la investigación y en la intervención social. Respecto al TS, esta relación supone que la producción del conocimiento parte primero de la deconstrucción de los orígenes de los problemas o dolores, esto es, de analizar y hacer conscientes sus orígenes y tener en cuenta su dimensión estructural. Posteriormente, también de manera compartida, se produce una fase de creatividad social en la que se plantean posibles soluciones a los problemas, posibles vías de acción, en las que el trabajador/a social y las metodologías son acompañantes y facilitadores. El objetivo es que, superando el individualismo y la culpabilidad, se produzca la transformación individual y colectiva. La sociopraxis parte de una concepción distinta de las relaciones sociales y aplicada al TS, de las que establece el profesional y el académico con sus destinatarios y compañeros; las metodologías participativas le dotan de herramientas para que desde esa concepción se posibilite la producción colectiva del conocimiento y los procesos de cambio. Puesto que los problemas son sociales, no individuales, y puesto que la sociopraxis y las metodologías participativas apuestan por la inteligencia grupal, por la producción compartida de conocimiento y sentido, los casos tratados por el TS tienen siempre una dimensión comunitaria. El TS, como la IAP, tiene su sentido, y se hace, en las redes. 
De esta manera, la sociopraxis y las metodologías participativas posibilitan una conexión entre las potencialidades de cambios que se producen en lo micro con cambios que repercuten en la sociedad en su conjunto. El TS se ejerce en el barrio, en la comunidad, desde los servicios sociales, por lo que la sociopraxis y la práctica de las metodologías participativas se convertirían en puentes para conectar de manera activa y posibilitar las transformaciones desde el ámbito local a una escala mayor. La cotidianidad y los espacios locales son lugares privilegiados desde donde atender los problemas sociales, desde los que combatir las realidades injustas, la vulnerabilidad y la exclusión social. El salto desde los ámbitos locales a ámbitos más amplios puede seguir la lógica de pensar, vivir y hacer de otra manera, en la práctica profesional y en la vida cotidiana. La capacidad de transformar la realidad social de arriba abajo parece más compleja, pues el peso de lo institucional plantea la necesidad de cambios de gran calado, grandes movilizaciones, incluso revoluciones. El camino opuesto parece más sencillo - pensarlo y producirlo_- pues se produce en el día a día. Más allá de la importancia y la capacidad demostrativa de los «desbordes» y de ciertos acontecimientos que transforman pero que son a su vez el resultado de transformaciones previas, son la cotidianidad, los espacios locales, comunitarios, de vecindad, desde donde se construyen, se producen, sociedades más justas (Pleyers y Álvarez-Benavides, 2019).

La crisis, sus consecuencias prolongadas en el tiempo más allá de la recuperación macroeconómica, se configuran como un escenario de oportunidades para la ciudadanía y para el TS. Además, la adaptación al EEES le confiere una cobertura en la que desarrollar de forma amplia y creativa todas estas potencialidades. Así, el TS debe beber de la vía de la subjetividad y la de la razón — pensando, visibilizando y posibilitando otros mundos posibles - y reformular su ser y su proceder desde la práctica cotidiana y desde la academia, desde los servicios sociales y desde la universidad. El TS, por el lugar que ocupa en nuestras sociedades, por su ontología y su deontología, es una práctica científica y profesional central en los procesos de cambio y los trabajadores/as sociales son actores imprescindibles para llevarlos a cabo.

\section{BIBLIOGRAFÍA}

Adelman, C. (1993). «Kurt Lewin and the Origins of Action Research», Educational Action Research (1:1), pp.: 7-24. DOI: 10.1080/0965079930010102

Álvarez-Benavides, A. (2005). «La globalización según Bourdieu». Cuadernos de Trabajo social, (18), pp. 121-131. 
- (2012). «Bourdieu and the crisis of global capitalism». Revista Latina de Sociología (2), pp. 5-22.

Anaut-Bravo, S. (2016). «La primera experiencia en España en formación de posgrado en Trabajo Social: la Universidad Pública de Navarra». REDU. Revista de Docencia Universitaria, 14(2), pp. 293-313. DOI: https://doi.org/10.4995/redu.2016.5985

Ander-Egg, E. y Kruse, H. (1984). Del paternalismo a la conciencia de cambio, Buenos Aires: Ecro.

Barbero, J. M. (2002). El Trabajo Social en España. Zaragoza: Mira Editores.

Berger, P., Luckmanm, T. (1999). La construcción social de la realidad. Buenos Aires: Amorrortu.

Boal, A. (2013). Teatro del oprimido. Barcelona: Alba Editorial.

Borda, O. Fals (1979). «Introducción». En El problema de cómo investigar la realidad para transformarla, Bogotá: Tercer Mundo, pp. 11-57.

Brandão, C. Rodrigues (2015). «Educación pública, educación alternativa educación popular y educación del campo. Caminos y convergencias desvíos y divergencias», Polifonías Revista de Educación, Año IV (7), pp. 21-68

Brezmes, M. (2008). El Trabajo Social en España. Murcia: Editum.

Bruyn, S. (1963). «The methodology of participant observation». Human Organization, 22(3), pp. 224-235.

Camas, V. y Martínez, A. (2015). «Investigación-acción participativa y documentales etnográficos: reflexiones epistemológicas y apuntes teóricos». En Sierra F. y Montero, D. (eds.). Videoactivismo y movimientos sociales. Barcelona: Gedisa.

CIMAS (2015). Metodologías participativas. Sociopraxis para la creatividad social, Madrid, Dextra Editorial.

Colomer, M. (1979). «Método de trabajo social», RTS: Revista de treball social, (75) pp: 4-48.

- (1990). «Trabajo Social en España en la década de los 70». Revista de Servicios Sociales y Política Social, (20) pp. 6-12.

Curbelo, A. y Hernández, L. (2017). Otro Trabajo Social es posible. Construyendo Ciudadanía/14. Madrid: CIMAS.

Del Prado, L. y Rivero, S. (2019) «Comunidad y participación: debates desde la profesión del trabajo social», en Paño, P., Yáñez, R, y Suárez E. (coord.): Procesos y Metodologías Participativas Reflexiones y experiencias para la transformación social; Buenos Aires: CLACSO-UDELAR.

Freire, P. (1982). La educación como práctica de la libertad. México: Siglo XXI.

Garrido, F. J. (2005). Desarrollo sostenible y Agenda 21 Local. Prácticas, Metodología y Teoría. Madrid: IEPALA/CIMAS. 
Gil Parejo, M. (2004). El protagonismo de la organización colegial en el desarrollo del trabajo social en España. Madrid: Siglo XXI.

- (2004a). «Del asistencialismo a la profesionalización. Un análisis del Trabajo Social en España desde la literatura profesional». Miscelánea Comillas: Revista de Ciencias Humanas y Sociales (62)120, pp. 273-328.

- (2005). «El sistema de créditos europeo y la titulación de Trabajo Social». Humanismo y Trabajo Social (4), pp. 47-63.

- (2010). Los inicios de la construcción del Sistema Público de Servicios Sociales desde la perspectiva del Trabajo Social. Unos años prodigiosos, 1978-1988; Miscelánea Comillas: Revista de Ciencias Humanas y Sociales, 68 (132), pp. 185-209

- (2014). «Contribuciones a la institucionalización del trabajo social en España: de los primeros ensayos a las primeras tesis doctorales». Miscelánea Comillas. Revista de Ciencias Humanas y Sociales (72), 140-141, pp. 169-190.

Holloway, J. (2002). Change the world without taking power. Londres: Pluto Press

Idareta Goldaracena, F.; Úriz Pemán, M. J. y Viscarret Garro, J. J. (2017). «150 años de historia de la ética del Trabajo Social en España: periodización de sus valores éticos». Cuandernos de Trabajo Social, 30(1), pp. 37-50. DOI: https://doi.org/10.5209/ CUTS.52428

Lamo de Espinosa, Emilio (2003). «¿Para qué la ciencia social?». En Giner, Salvador (coord.): Teoría sociológica moderna, Madrid: Ariel.

López de Ceballos, P. (1987). Un método para la investigación-acción participativa, Madrid: Popular.

Marrow, A. J. (1977). The practical theorist: The life and work of Kurt Lewin. Nueva York: Teachers College Press.

Martín Cano, M. C. y De la Fuente Robles, Y. María. (2013). «Trabajo Social en el Espacio Europeo de Educación Superior: el caso español». Documentos de trabajo social: Revista de trabajo y acción social (53), pp. 91-107.

Martín Palomo, M. T. (2008) «'Domesticar’ el trabajo: una reflexión a partir de los cuidados». Cuadernos de Relaciones Laborales, 26 (2). pp. 13-44.

Molina, V. (1994). Las Escuelas de Trabajo Social en España (1932-1983), Comillas: Universidad Pontificia de Comillas.

Montañés Serrano, M. (2011). Metodología y técnica participativa: teoría y práctica de una estrategia de investigación participativa (vol. 127). Barcelona: Editorial UOC. Montañés Serrano, M. y Martín Gutiérrez, P. (2017). «De la IAP a las Metodologías Sociopráxicas». Hábitat y Sociedad (10), pp. 35-52. http://dx.doi.org/10.12795/HabitatySociedad.2017.i10.03 
Montes del Castillo, Á. (2000). «Antropología, investigación-acción y trabajo social», en Mártinez, J. M. (coord..): Para el trabajo social: aportaciones teóricas y prácticas. Madrid: Maristán.

García Montes, N. y Arnanz Monreal, L.. (2019). «Metodologías participativas para la planificación de la sostenibilidad ambiental local. El caso de la Agenda 21». Empiria: Revista de metodología de ciencias sociales (44), pp. 109-133. DOI: https://doi. org/10.5944/empiria.44.2019.25354

Navarro Llobregat, B. (2013). «Tipología de clientes en Trabajo Social: una herramienta para la mejora de la intervención profesional». Documentos de trabajo social: Revista de trabajo y acción social (52), pp. 31-54.

Pleyers, G. (2019). Movimientos sociales en el siglo XXI. Perspectivas y herramientas analíticas. Barcelona: Icaria.

Pleyers, G. y Álvarez-Benavides, A. (2019). «La producción de la sociedad a través de los movimientos sociales». En: Revista Española de Sociología, 28 (1), Madrid: Federación Española de Sociología. pp. 141-149. https://doi.org/10.22325/fes/ res. 2018.53

Quintero-Londoño, S. (2014). «El «Método Caldas» y la reconceptualización del trabajo social». Revista Eleuthera (10), pp. 182-203.

- (2018). «Contexto, tendencias y actores de la Reconceptualización». Revista Eleuthera (20), pp. 179-198. DOI: 10.17151/eleu.2019.20.10.

Rahman, M. A. y Fals Borda, O. (1988). «Romper el monopolio del conocimiento: Situación actual y perspectivas de la Investigación-Acción Participativa en el mundo». Análisis Político (5), pp. 46-55.

Sanz Cintora, Á. (2001). «Acción social y Trabajo Social en España: una revisión histórica». Acciones e Investigaciones Sociales (13), pp. 5-42. https://doi.org/10.26754/ ojs_ais/ais.200113201

Sassen, S. (2003). Contrageografias de la globalización. Género y ciudadanía en los circuitos transfronterizos. Madrid: Traficantes de sueños.

Schutz, A. (1993). La construcción significativa del mundo social: introducción a la sociología comprensiva, Barcelona: Paidós.

Socas, J.; Savedra, L. y Hernández, G. (2003): «La técnica del flujo-grama: apuntes desde la práctica». En Cuadernos CIMAS-Observatorio Internacional de Ciudadanía y Medio Ambiente Sostenible. En línea: http://www.redcimas.org/wordpress/ wp-content/uploads/2014/02/m_La-tecnica-del-flujograma.pdf

Sucari, J. (2017). «El documental social participativo: el protagonista como sujeto de la historia». Obra digital: revista de comunicación (12), pp. 69-85. DOI: https://doi. org/10.25029/od.2017.112.12 
Thomas, W. y Znaniecki, F. (2004). El campesino polaco en Europa y en América. Madrid: Centro de Investigaciones Sociológicas.

Vázquez Aguado, O. (2005). «El espacio europeo de educación superior y el trabajo social en España». Portularia (1), pp. 239-254.

Vera Quiroz, A. (2020). «Trabajo Social chileno y la reconceptualización: Apuntes para re-mirar». Nueva Acción Crítica (8), pp. 131-134.

Villasante, T. R. (1996). «La construcción (sustentable) de un cambio civilizatorio (equilibrador)». Política y Sociedad (23), pp. 193-208

- (2007a). «Una articulación metodológica: desde textos del Socio-análisis, I (A) P, F. Praxis, Evelyn F. Keller, Boaventura S. Santos, etc.». Política y sociedad, 44 (1), pp. 141-157.

- (2007b). «Seis saltos que practicamos por los caminos de la complejidad social». Política y sociedad, 44 (1), pp. 73-94.

- (2014). Redes de vida desbordantes. Fundamentos para el cambio desde la vida cotidiana. Madrid: Editorial Catarata.

- (2015): «Conjuntos de acción y grupos motores para la transformación ambiental». Política y Sociedad 52 (2), pp. 387-408 DOI: https://doi.org/10.5209/rev_ POSO.2015.v52.n2.45204

Villasante, T. R. y Martín Gutiérrez, Pedro (2007). «Redes y conjuntos de acción: para aplicaciones estratégicas en los tiempos de la complejidad social». Redes. Revista hispana para el análisis de redes sociales (11), pp. 1-22. DOI: https://doi. org $/ 10.5565 /$ rev/redes. 87

Villasante, T. R., Garrido, Francisco Javier y Hernández, Dolores (2002). Metodologías y presupuestos participativos (vol. 3). Madrid: IEPALA Editorial.

Wieviorka, M. (2008). Neuf leçons de sociologie. París: Robert. 